\title{
INFLUENCE OF GROOVES AND POSITION OF ELECTRODES ON THE TEMPERATURE DISTRIBUTION OF A FLAT MOLD USING HIGH-FREQUENCY DIRECT RESISTANCE HEATING
}

\author{
KAZUTO TANAKA, YOSHIKI FURUKAWA, TSUTAO KATAYAMA, KIMITAKA WATANABE, \\ MASATAKA KAWAGUCHI \& HIDEYUKI KUWAHARA \\ Department of Biomedical Engineering, Doshisha University, Japan
}

\begin{abstract}
Carbon Fiber Reinforced Thermoplastics (CFRTP), which are superior in recyclability and mechanical properties, are expected to be the replacement materials for traditional metal. To increase the application of CFRTP, it is necessary to develop a low-cost and high-speed molding method. A high-frequency direct resistance heating method, which heats only the mold surface rapidly by skin effect, has been developed and shows better energy consumption than the conventional method using a heater. With this heating method, due to the edge effect and the proximity effect between the mold and the power supply wiring, temperature distribution of the mold surface is non-uniform, which is a major issue to be solved. In this study, to obtain uniform temperature distribution of the flat mold, the influences of grooves and position of the electrodes on the temperature distribution of the mold surface were clarified by FEM analysis. Temperature at the edges, which is higher than the flat area due to the edge effect, can be lowered by positioning of grooves in parallel with the current at the mold edges, and by cancelling the magnetic fields of currents, which flow on both sides of the grooves. Furthermore, the temperature difference of the mold can be reduced by moving the electrodes from the current concentration area.

Keywords: Carbon Fiber Reinforced Thermoplastics, direct resistance heating, flat plate mold, temperature distribution, current density distribution, edge effect, proximity effect, grooves, electrodes position, FEM analysis.
\end{abstract}

\section{INTRODUCTION}

Recently, in the automotive industry, weight of the car body must be reduced to assist reduction of $\mathrm{CO}_{2}$ emissions [1]. Carbon Fiber Reinforced Thermoplastics (CFRTP) are expected to be candidates for replacing traditional metal materials as they have many superior mechanical properties such as high-specific strength and high-specific-modulus [2].

In the molding of CFRTP, in order to realize a short production cycle, the development of a high-speed mold heating method is required. For the high-speed mold heating method, a high frequency alternating current, which enables high-speed heating to the surface due to the skin effect [3] is being highlighted greatly. Generally, as the heating technology using high frequency alternating current for metal materials, induction heating [4] and direct resistance heating are popular. Induction heating is a method of applying a high frequency alternating current through the coil to induce current in the metal materials [5], but it has the drawback of requiring equipment such as a coil. On the other hand, direct resistance heating is a method of connecting a power source directly to the metal material and applying current [6], so it has the advantages that the equipment cost can be suppressed and that the power loss is low [7]. By applying direct resistance heating to the mold for CFRTP molding, simplification of the equipment and facilities as well as high-speed molding can be expected [8].

In our previous study, FEM analysis of temperature distribution of a flat mold by direct resistance heating reported a problem that uneven temperature distribution occurs on the 
mold surface due to the edge effect and the proximity effect between the power supply wiring and the mold.

In this study, in order to suppress the effects of edge effect and proximity effect when a flat mold is heated by using high frequency direct resistance heating, the influences on mold surface temperature distribution by adding grooves at both edges of the mold and by shifting the position of the electrodes were clarified.

\section{ANALYSIS MODEL AND ANALYSIS CONDITION}

\subsection{Analysis models}

Fig. 1 shows the overall view of the analysis model. A SUS430 rectangular parallelepiped mold with a width of $130 \mathrm{~mm}$, a length of $240 \mathrm{~mm}$, and a thickness of $30 \mathrm{~mm}$, which has copper L-shaped electrodes in a width of $130 \mathrm{~mm}$ and a thickness of $8 \mathrm{~mm}$ at both sides, is a standard mold (called as Normal). As shown in Fig. 1, it is assumed to mold CFRTP with a width of $100 \mathrm{~mm}$ and a length of $200 \mathrm{~mm}$, and the center line of the mold surface will be called as Line A. The electrodes are connected to the power supply by copper braided wires and feeders. The number of elements was 5257 in Normal mold.

In order to clarify the effect of grooves on the temperature distribution of the mold, models with grooves of widths of $2 \mathrm{~mm}$ and $5 \mathrm{~mm}$ were modelled as shown in Fig. 2. The position of grooves is $10 \mathrm{~mm}$ away from the edges on the long side of the Normal mold. The number of elements of each mold model is 9500 in the mold with a $2 \mathrm{~mm}$ groove and 6812 in the mold with a $5 \mathrm{~mm}$ groove.

In order to clarify the influence of the electrode position on the temperature distribution of the mold, by using electrodes with half width of the Normal mold $(65 \mathrm{~mm})$, two models were used with the electrode position closer to the power source (Inner) and farther from the power source (Outer). The number of elements of each mold model is 4820 in Inner mold and 5013 in Outer mold. Fig. 3 shows these models as (a) Normal; (b) Inner; and (c) Outer.

\subsection{Analysis conditions}

For the analysis, a general-purpose engineering simulation software COMSOL Multiphysics ${ }^{\circledR}$ was used, and a coupled analysis of electromagnetic and heat transfer was performed using Electric and Induction Current (AC/DC Module) and General Heat Transfer (Heat Transfer Module). The electromagnetic analysis was carried out by quasi-steady analysis while the heat conduction analysis was carried out by transient analysis. The boundary condition between each material was continuous in both analyses of electromagnetic and heat conduction. The contact resistance between the electrode and the mold was not considered. In order to consider the heat radiation into the air, a layer of air was set around the mold, the outermost layer of the air was fixed at $20^{\circ} \mathrm{C}$. Tetrahedral elements were used, and boundary layer mesh was applied to the mold surface. Table 1 shows the relative permeability, electrical conductivity, and thermal conductivity of each material used in the analysis. The temperature distribution and the current density distribution when power was supplied to the copper feeder of the mold for 60 seconds were calculated. For the alternating current, the frequency was $10 \mathrm{kHz}$ and the power supply was $10 \mathrm{~kW}$. 


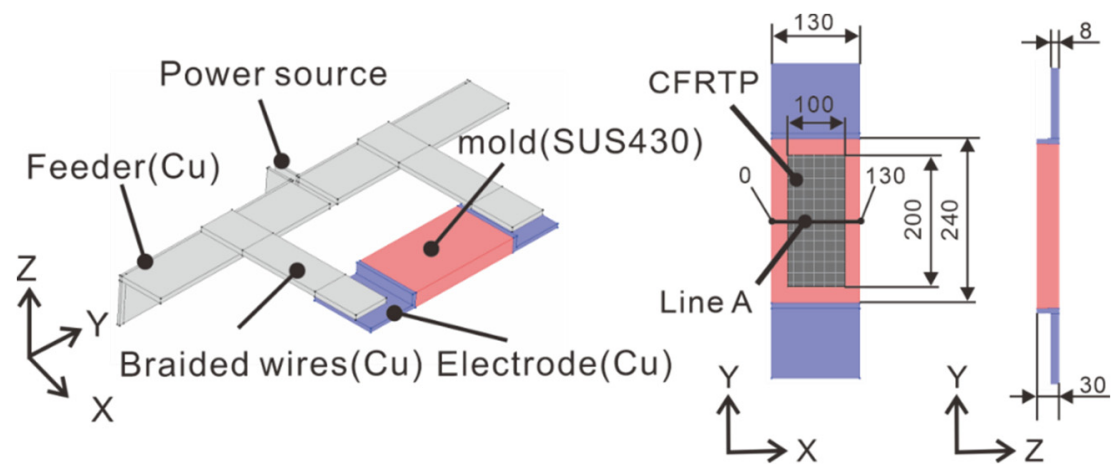

Figure 1: FEM model.

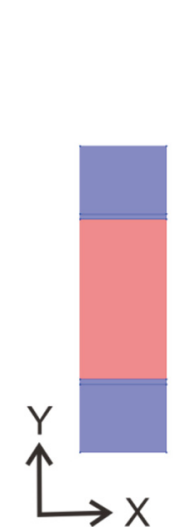

(a)

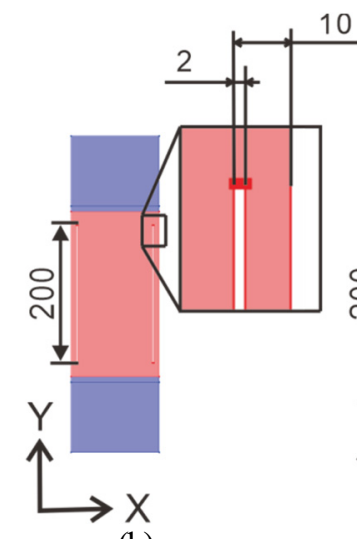

(b)

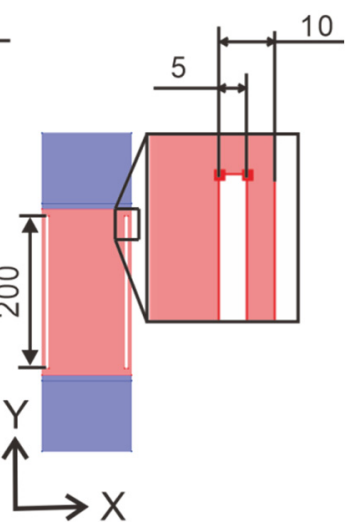

(c)

Figure 2: FEM models with grooves. (a) Normal; (b) $2 \mathrm{~mm}$; and (c) $5 \mathrm{~mm}$.

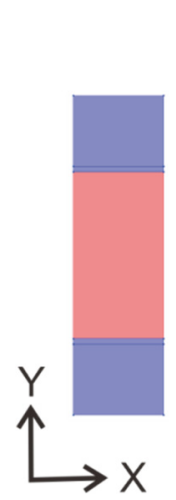

(a)

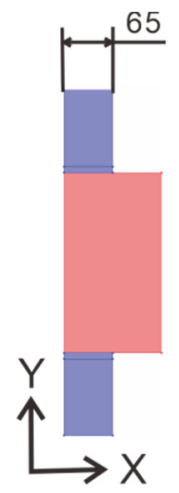

(b)

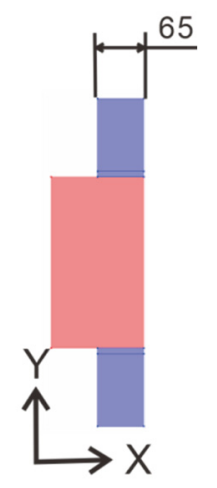

(c)

Figure 3: $\quad$ FEM models with electrodes at different positions. (a) Normal; (b) Inner; and (c) Outer. 
Table 1: Electrical properties.

\begin{tabular}{|l|c|c|c|}
\hline & SUS430 & Copper & Air \\
\hline Relative magnetic permeability & 122.4 & 1 & 1 \\
\hline Electric conductivity $(\mathrm{S} / \mathrm{m})$ & $1.67 \times 10^{6}$ & $5.99 \times 10^{7}$ & 0 \\
\hline Thermal conductivity $(\mathrm{W} /(\mathrm{m} / \mathrm{K}))$ & 25.6 & 400 & 0.257 \\
\hline
\end{tabular}

\section{RESULTS AND DISCUSSION}

\subsection{Effect of grooves at both edges of the mold on the temperature distribution}

Figs 4, 5 and 6 show the current density distribution, temperature distribution and magnetic flux density distribution along Line A on the mold surface for the Normal model and the grooved models. In the Normal model, the current densities are high at the edges of Line A, and the temperature is accordingly high. This higher current density at the edges is considered to be created by the edge effect [9]. In order to compare the Normal model with the grooved models, the points inside $10 \mathrm{~mm}$ from the edges of the long side of the mold, which correspond to the inner ends of the groove on Line A of each model, are defined as the ends, and referred to as I for Normal, II for $5 \mathrm{~mm}$ and III for $2 \mathrm{~mm}$-groove in the figures. Comparing the current densities at the ends between the Normal (Fig. 4, I) and the grooved models (Fig. 4, II \& III), the current densities at the ends of the grooved models are low. In addition, comparing the current densities at the ends of the grooved models with a width of $2 \mathrm{~mm}$ (Fig. 5, III) and of $5 \mathrm{~mm}$ (Fig. 5, II), the current density for $2 \mathrm{~mm}$ is lower. The smaller the groove width becomes, the lower the current density is confirmed at the ends.

Furthermore, comparing the magnetic flux densities at the ends between the Normal (Fig.6, I) and the grooved models (Fig. 6, II and III), the magnetic flux densities for grooves is lower. In addition, comparing the magnetic flux density at the ends of the grooved models with a width of $2 \mathrm{~mm}$ (Fig. 6, III) and of $5 \mathrm{~mm}$ (Fig. 6, II), the magnetic flux density for $2 \mathrm{~mm}$ is lower, and the smaller the groove width becomes, the lower the magnetic flux density is confirmed at the ends.

According to these results, it is considered that the magnetic fields cancel each other out due to the current flowing in the same direction on both sides of the groove [10]. At the same time, the magnetic flux density decreases on both sides of the groove, and the current density decreases accordingly. In addition, it is considered that the smaller the groove width becomes, the stronger the magnetic fields cancel each other out because of smaller distance between the currents, resulting in a lower current density at the end.

From the above results, the current density becomes high due to the edge effect for the Normal model, but the current density can be suppressed by providing grooves in the mold, which show lower temperature at the ends. Moreover, the influence can be further increased by reducing the groove width. 
$\left[\times 10^{7}\right]$
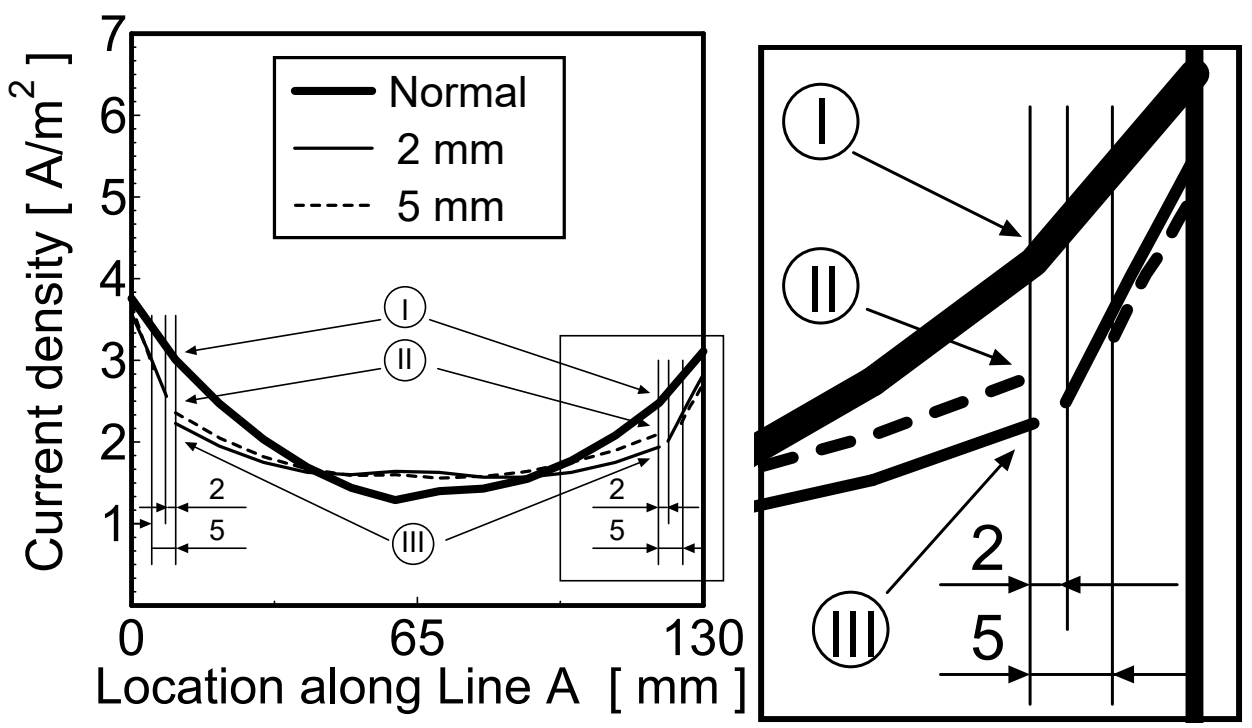

Figure 4: Current density distribution of Line A (with/without grooves).
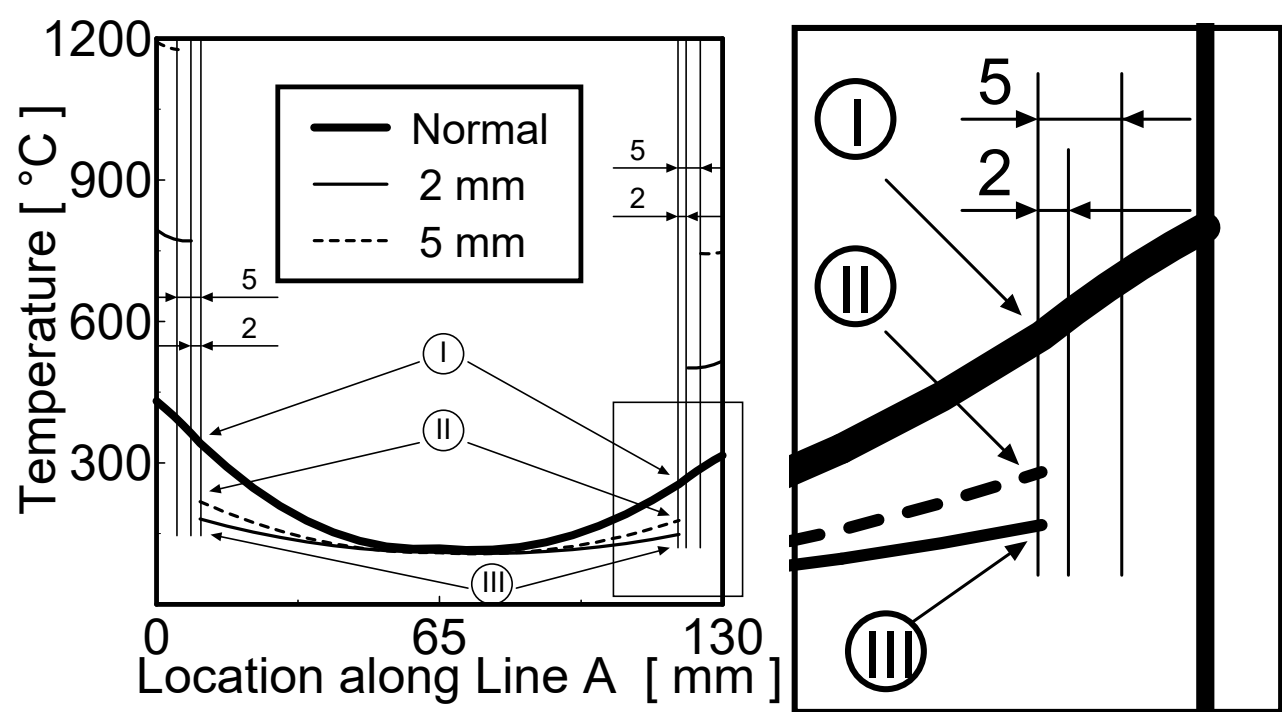

Figure 5: Temperature distribution of Line A (with/without grooves). 


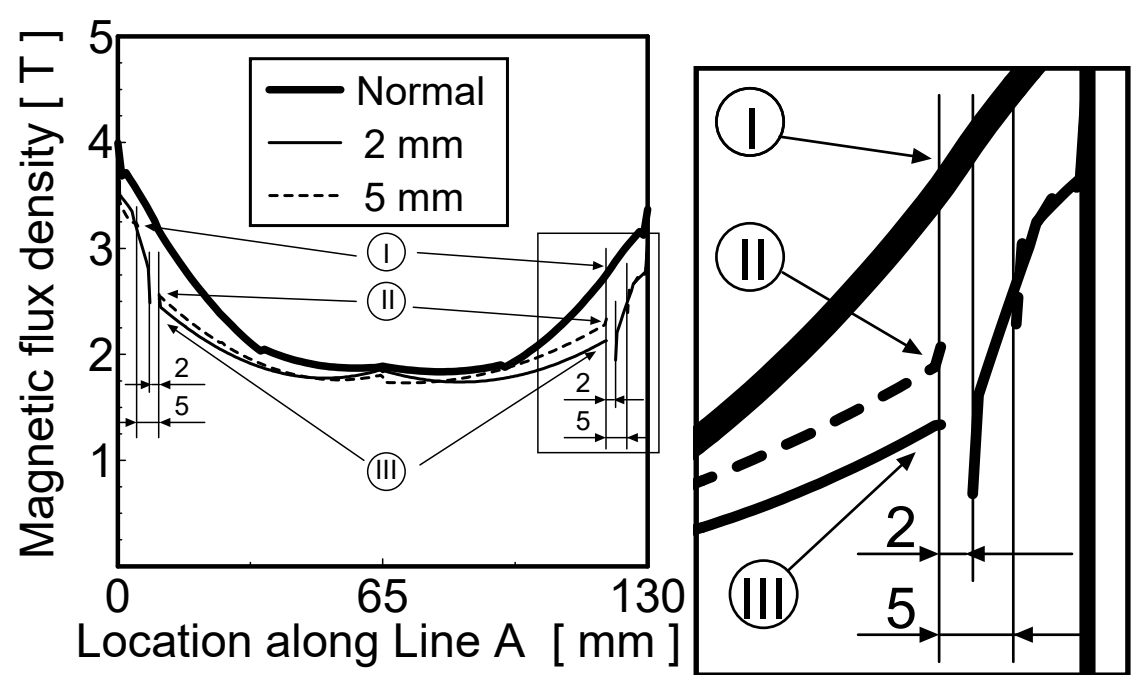

Figure 6: Magnetic flux density distribution of Line A (with/without grooves).

3.2 Effect of controlling the position of the electrodes attached to the mold on the temperature distribution

Figs 7 and 8 show the current density distribution and temperature distribution at Line A on the mold press surface in each model. Here, on Line A, the point at $x=0$ is referred to as the edge near the power source, and the point at $\mathrm{x}=130$ is referred to as the edge far from the power source. Table 2 shows the temperatures and their difference at the edge near the power source and the edge far from the power source in each model.

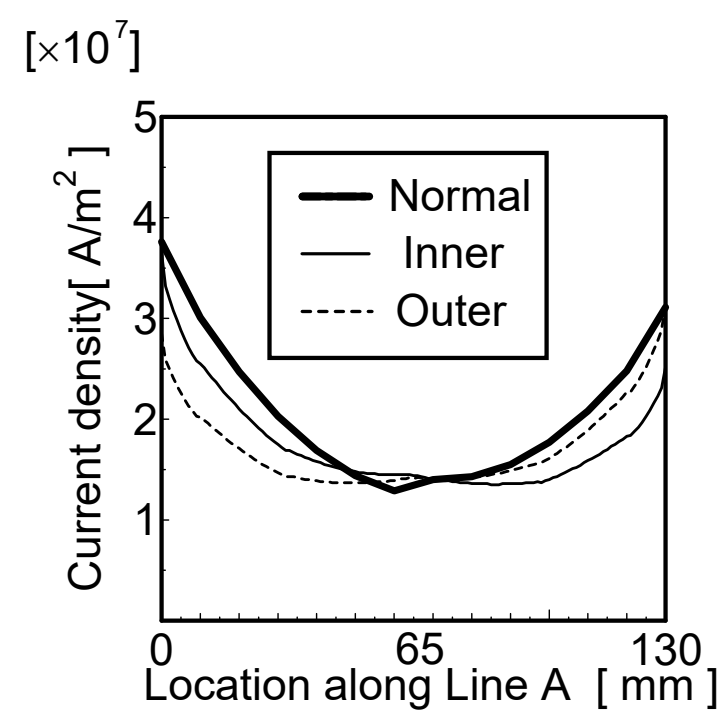

Figure 7: Current density distribution of Line A (with electrodes at different positions). 


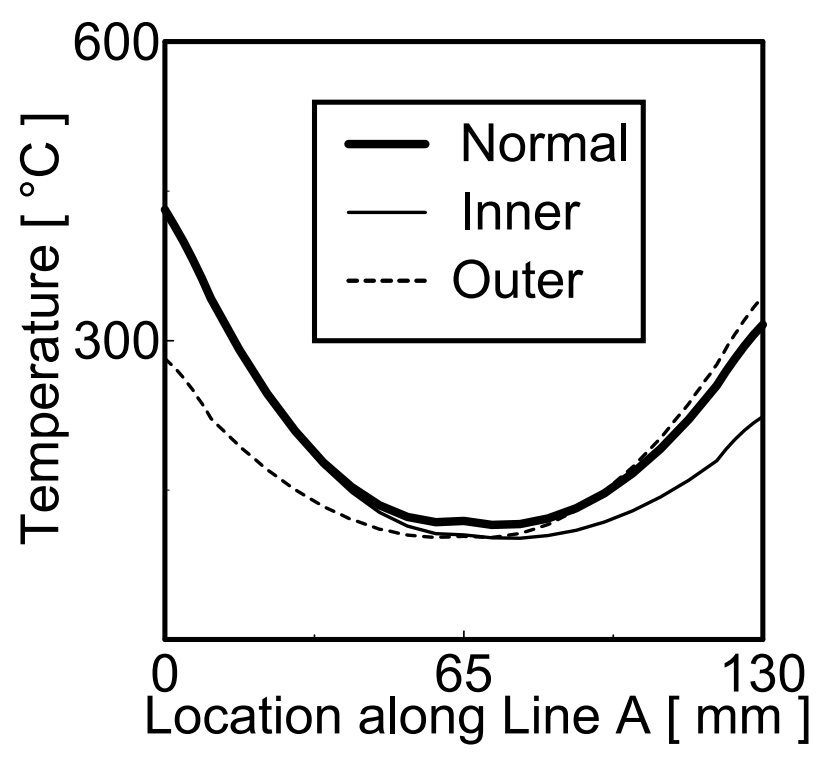

Figure 8: Temperature distribution of Line A (with electrodes at different positions).

\section{Power source side}

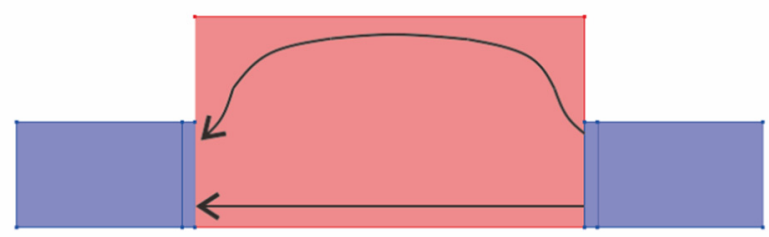

Figure 9: Possible conductive path for Outer position.

In the Normal model, the edge near the power source has higher current density than the edge far from the power source, and the temperature is accordingly higher. The root-cause can be considered to be the proximity effect.

Comparing the current densities between the models in which the electrode position is closer to the power source (Inner) and farther from the power source (Outer), Outer has a larger current flowing at the end far from the power source. Furthermore, comparing the temperature difference between both edges of Normal and Outer, it was $115.2^{\circ} \mathrm{C}$ in Normal, while it was $63.0^{\circ} \mathrm{C}$ in Outer, which is about $45 \%$ lower.

As shown in Fig. 9, by shifting the electrodes away from the power source, the path of the edge far from the power source becomes shorter than the path of the edge near the power source. Since a large amount of current flows in the path with a short distance, the current density at the edge far from the power source becomes high and the temperature difference at both edges can be reduced. From the above, the proximity effect can be suppressed by shifting the position of the electrodes away from the power source. 
Table 2: Temperature at both edges and their temperature differences.

\begin{tabular}{|l|c|c|c|}
\hline & (a) Normal & (b) Inner & (c) Outer \\
\hline Inner edge temperature $\left({ }^{\circ} \mathrm{C}\right)$ & 431.2 & 434.4 & 281.8 \\
\hline Outer edge temperature $\left({ }^{\circ} \mathrm{C}\right)$ & 316.0 & 223.7 & 344.8 \\
\hline Temperature difference $\left({ }^{\circ} \mathrm{C}\right)$ & 115.2 & 210.7 & 63.0 \\
\hline
\end{tabular}

\section{CONCLUSION}

In this study, in order to suppress the effects of the edge effect and proximity effect that occur when a flat mold is heated by using high frequency direct resistance heating, the influence on mold surface temperature distribution by adding grooves at both edges of the mold and by shifting the position of the electrodes were clarified. The findings obtained are shown below.

1. By adding grooves at both edges of the mold, the magnetic fields cancel each other out by the currents flowing in the same direction on both sides of the grooves, and the temperature of the edge, that has become higher due to the edge effect, can be lowered. Furthermore, by reducing the groove width, the temperature of the edge can be further lowered.

2. By shifting the position of the electrodes to be away from the power source, a large amount of current flows through a short path at the mold ends far from the power source. Therefore, the temperature difference at both ends, caused by the proximity effect, can be reduced.

\section{REFERENCES}

[1] Daisho, Y., Prospect on environmental and energy vehicle technologies - Improving conventional technologies and electrifying the vehicle. NTN TECHNICAL REVIEW, 79, 2011.

[2] Baba, S., Continuous fiber reinforced thermoplastics CFRTP-GFRTP and market. Journal of the Japan Society for Precision Engineering, 81(6), pp. 503-506, 2015.

[3] Kuroda, K., Saito, Y. \& Hori, K., Shape optimization of high frequency current carrying conductor by skin effect visualization. Journal of the Visualization Society of Japan, 26(1), 2006.

[4] Wu, C.Y., Jin, X.L. \& Zhou, Y.M., Recent progress of induction heating technology in Baosteel. IOP Conference Series: Materials Science and Engineering, 424, 012061, 2018.

[5] Tanaka, K., Kohashi, N., Kinoshita, Y., Katayama, T. \& Uno, K., Compression molding of carbon fiber reinforced thermoplastics using non-woven stitched multiaxial cloth by means of induction heating system. Journal of the Society of Materials Science, 58(7), pp. 642-648, 2009. 
[6] Hamada, K., Isaka, K., Doi, D., Yonemitsu, Y. \& Iwasaki, S., Application of the direct resistance heating for stainless steel/aluminum clad manufacturing process. Tetsu-toHagane, 88(2), pp. 16-22, 2002.

[7] Itoh, H., Direct current heating method and points to notice. Journal of Surface Science and Nanotechnology, 19(6), pp. 417-418, 1998.

[8] Tanaka, K., Harada, R., Uemura, T., Katayama, T. \& Kuwahara, H., Rapid pipe molding process of carbon fiber reinforced thermoplastics by high-frequency direct resistance heating. WIT Transactions on the Built Environment, vol. 112, WIT Press: Southampton and Boston, pp. 133-139, 2010.

[9] Okabe, T., Yasuda, K. \& Nakata, K., Dynamic observations of welding phenomena and finite element analysis in high frequency electric resistance welding. Japan Welding Society, 32(3), pp. 156-163, 2014.

[10] Tanaka, K., Nakatsuka, J., Katayama, T. \& Kuwahara, H., FEM analysis of temperature distribution of flat mold by direct resistance heating method. Journal of the Society of Materials Science, Japan, 67(3), pp. 367-374, 2018. 